\title{
MK-2206 co-treatment with 5-fluorouracil or doxorubicin enhances chemosensitivity and apoptosis in gastric cancer by attenuation of Akt phosphorylation
}

\author{
This article was published in the following Dove Press journal: \\ OncoTargets and Therapy \\ 19 July 2016 \\ Number of times this article has been viewed
}

\section{Piaopiao Jin ${ }^{1,2}$ \\ Chi Chun Wong ${ }^{3}$ \\ Sibin $\mathrm{Mei}^{\mathrm{I}}$ \\ Xingkang $\mathrm{He}^{4}$ \\ Yun Qian ${ }^{4}$ \\ Leimin Sun'}

'Department of Gastroenterology, Sir Run Run Shaw Hospital, Zhejiang University School of Medicine,

Hangzhou, ${ }^{2}$ Department of

Gastroenterology, The First Affiliated Hospital, Wenzhou Medical University, Wenzhou, Zhejiang, ${ }^{3}$ Department of Medicine and Therapeutics, Chinese University of Hong Kong, Hong

Kong, ${ }^{4}$ Institute of Gastroenterology,

Zhejiang University, Hangzhou,

Zhejiang, People's Republic of China

\begin{abstract}
The anticancer effect of MK-2206, an Akt inhibitor, has been explored in some types of cancers, but its effect on gastric cancer is unclear. In this study, we aimed to investigate its anticancer effect in gastric cancer cells. Cell viability and colony formation assays showed that MK-2206 effectively inhibited the proliferation of SGC-7901 and MKN45 cells. The $50 \%$ inhibitory concentration values after 24,48 , and 72 hours' treatment were $22.92,13.68$, and $8.55 \mu \mathrm{M}$ in SGC-7901 cells and 19.21, 13.10, and 9.11 $\mu \mathrm{M}$ in MKN45 cells, respectively. Treatment with MK-2206 induced apoptosis in SGC-7901 cells as indicated by flow cytometry assay. The combination indexes of MK-2206 and doxorubicin were 0.59 in SGC-7901 cells and 0.57 in MKN45 cells, whereas for 5-fluorouracil (5-FU) the indexes were 0.17 in SGC-7901 cells and 0.73 in MKN45 cells, indicating that MK-2206 could work synergistically with doxorubicin or 5 -FU to inhibit cell growth. Furthermore, a small dose $(1 \mu \mathrm{M})$ of MK-2206 co-treatment with doxorubicin or 5-FU was sufficient for complete inhibition of chemotherapeutic alteration of phosphorylated Akt expression and significant enhancement of pro-apoptosis effect through the activation of caspase pathway. Therefore, MK-2206 effectively inhibits gastric cancer cell growth by attenuation of Akt phosphorylation and synergistically enhances the antitumor effect of doxorubicin and 5-FU via caspase-dependent apoptosis.
\end{abstract}

Keywords: MK-2206, Akt pathway, apoptosis, chemotherapy, caspase, gastric cancer

\section{Introduction}

Gastric cancer is one of the most fatal malignancies worldwide. It is estimated that a total of 952,000 new gastric cancer cases and 723,000 related deaths occurred in 2012, making gastric cancer the fifth most common malignancy and the third leading cause of cancer-related deaths in the world. ${ }^{1}$ Although the promotion of endoscopic screening has helped to decrease gastric cancer mortality, the survival rate remains poor. Many patients are diagnosed at an advanced stage, as chemotherapy regimens are largely ineffective. As the first-line treatment for advanced gastric cancer, palliative chemotherapy can slightly prolong the median survival time to 7-10 months, but the 5 -year survival rate is only 5\%-15\%. ${ }^{2}$ Moreover, chemo-related toxicity and resistance limited efficiency and further use of chemotherapy. With an improved understanding of the molecular mechanisms of gastric cancer, medical scientists have made substantial efforts to identify novel and effective methods for targeted therapies. However, except for trastuzumab, which targets gastric cancer with ERBB2 amplification, no other targeted therapy has been approved for gastric cancer thus far.
Correspondence: Leimin Sun Department of Gastroenterology, Sir Run Run Shaw Hospital, Zhejiang University School of Medicine, 3 East Qingchun Road, Hangzhou 310016 , Zhejiang,

People's Republic of China

Tel +86 57I 86090073

Email sunleimin@yahoo.com 
Phosphiotidylinositol-3-kinase (PI3K)/Akt signaling plays a vital role in regulating cell proliferation and survival in cancer. ${ }^{3}$ The activation of the PI3K/Akt pathway is initiated by the binding of growth factors to activate receptor tyrosine kinases, which phosphorylates PI3K. Activated PI3K catalyzes the phosphorylation of phosphotidylinositol-4, 5-bisphosphate (PIP2) to PIP3. As a second messenger, PIP3 is essential for the translocation of Akt to the plasma membrane, where it is activated by the phosphorylation of Thr308 and Ser473. ${ }^{4}$ Akt, also known as protein kinase B, consists of three isoforms, $\mathrm{Akt}_{1} / \mathrm{PK} \alpha, \mathrm{Akt}_{2} / \mathrm{PK} \beta$, and $\mathrm{Akt}_{3} /$ $\mathrm{PK} \gamma,{ }^{5}$ and is critical in phosphorylating a wide array of downstream substrates involved in cell growth, survival, apoptosis, and drug sensitivity.,

The aberrant activation of PI3K/Akt pathway is an important driver of cancer progression and chemoresistance, which may be mediated by various mechanisms including mutations in phosphoinositide-3-kinase catalytic $\alpha$-polypeptide (PIK3CA),${ }^{8}$ loss or inactivating mutations of the tumor suppressor gene phosphatase and tesin homolog (PTEN), ${ }^{9}$ overexpression of Akt/PKB isoforms, ${ }^{6}$ and the amplification of upstream receptors.

In gastric cancer, the PI3K/Akt pathway is frequently activated. Analysis of gastric cancer tissue by immunohistochemistry revealed that Akt and p-Akt expression levels were detected in $74 \%$ and $78 \%$ of the tumors, respectively. ${ }^{10}$ Their expression levels were found to be associated with tumor aggressiveness, depth of invasion, lymph node metastasis, and multidrug resistance. ${ }^{11,12}$ Moreover, $\mathrm{p}$-Akt expression may predict the clinical outcome of gastric cancer patients..$^{10}$ Thus, the PI3K/Akt pathway is an attractive therapeutic target for gastric cancer.

MK-2206, a new allosteric inhibitor of pan-Akt kinase, has been reported to augment the efficacy of conventional antitumor therapies in various cancer cells. ${ }^{13-17}$ MK-2206 is well tolerated in a phase I trial with evidence of Akt-signaling blockade. ${ }^{18}$ However, only limited studies have assessed MK-2206 effect on gastric cancer. Thus, the present study was undertaken to investigate the preclinical activity of MK-2206 in gastric cancer cells and the potential synergetic effect of MK-2206 in combination with two conventional chemotherapeutics, doxorubicin and 5-fluorouracil (5-FU).

\section{Materials and methods}

\section{Reagents and antibodies}

MK-2206 (Selleck Chemicals, Houston, TX, USA) was dissolved in dimethylsulfoxide at $10 \mathrm{mM}$ and stored at $-80^{\circ} \mathrm{C}$. 5-FU purchased from InvivoGen (San Diego, CA, USA) was dissolved in phosphate-buffered saline ( $\mathrm{pH}$ 7.4), and doxorubicin hydrochloride purchased from HisunPharm (Taizhou, People's Republic of China) was dissolved in sterile distilled water. Both drugs were stored at $-4^{\circ} \mathrm{C}$ and shielded from light.

Rabbit anti-Akt, p-Akt (Ser473), caspase-9, caspase-7, caspase-3, poly ADP ribose polymerase (PARP), cleaved caspase-3, cleaved caspase-7, and cleaved caspase-9 were purchased from Cell Signaling Technology (Danvers, MA, USA). $\beta$-Actin and glyceraldehyde-3-phosphate dehydrogenase (GAPDH) were purchased from Santa Cruz Biotechnology (Dallas, TX, USA).

\section{Cell culture}

Human gastric cancer cells, SGC-7901 and MKN45, were obtained from the Cell Bank of the Chinese Academy of Sciences (Shanghai, People's Republic of China) and maintained at $37^{\circ} \mathrm{C}$ in RPMI-1640 medium (Genom, Hangzhou, People's Republic of China) supplemented with $10 \%$ fetal bovine serum, $100 \mu \mathrm{g} / \mathrm{mL}$ ampicillin, and $0.1 \mathrm{mg} / \mathrm{mL}$ streptomycin, in a humidified atmosphere containing $5 \% \mathrm{CO}_{2}$ and $95 \%$ air.

\section{Cell viability assays}

Cells were seeded in 96-well plates at a density of $3 \times 10^{3}$ to $4 \times 10^{3}$ cells per well. After incubation for 20 hours, the cultural medium was replaced by $10 \%$ fetal bovine serum medium with different concentrations of selected drugs for further incubation for 24, 48, and 72 hours. Cell viability was determined with CellTiter 96 AQueous One Solution Cell Proliferation Assay (G3580, Promega, Madison, WI, USA) at a wavelength of $490 \mathrm{~nm}$. The optical density (OD) was measured by computer-controlled microplate analyzer (BioTek, Winooski, VT, USA). The inhibitory rate was calculated using the following equation:

$$
\mathrm{I} \%=\frac{1-\mathrm{OD}_{\mathrm{A}}}{\mathrm{OD}_{\mathrm{C}}} \times 100 \%
$$

where $\mathrm{I} \%$ is the inhibitory rate, $\mathrm{OD}_{\mathrm{A}}$ is the $\mathrm{OD}$ value of the wells culturing cells treated with drugs, and $\mathrm{OD}_{\mathrm{C}}$ is the $\mathrm{OD}$ value of the wells culturing cells treated with drug-free solutions. The $50 \%$ inhibitory concentration $\left(\mathrm{IC}_{50}\right)$ was calculated by nonlinear fitting.

\section{Cell colony formation assay}

SGC-7901 cells were plated in six-well plates at a density of 500 cells per well and treated with MK-2206 $(1 \mu \mathrm{M})$ or vehicle for 10 days. Culture medium was replaced every 2-3 days. Cells were fixed with methanol and stained with 
$0.1 \%$ crystal violet. Visible colonies containing at least 50 cells were counted. The colony formation efficiency was calculated as follows:

$$
\frac{\text { Number of colonies }}{\text { Number of cells inoculated }} \times 100 \%
$$

\section{Cell apoptosis}

SGC-7901 cells were treated with MK-2206 at concentrations ranging from 0 to $16 \mu \mathrm{M}$ for 72 hours. An Annexin-Vfluorescein isothiocyanate/propidium iodide (FITC/PI) apoptosis detection kit (KeyGEN Biotech, Nanjing, People's Republic of China) was used to measure apoptosis and necrosis in drug-treated cells according to the manufacturer's instruction, using an FACScan flow cytometer (BD Biosciences, San Jose, CA, USA). Viable cells were negative for both Annexin-V and PI (Annexin- $\left.\mathrm{V}^{-} / \mathrm{PI}^{-}\right)$, while late-stage apoptotic cells and necrotic cells were double-stained with Annexin- $\mathrm{V}$ and $\mathrm{PI}\left(\right.$ Annexin- $\left.\mathrm{V}^{+} / \mathrm{PI}^{+}\right)$and apoptotic cells were stained positive only with Annexin-V (Annexin- $\left.\mathrm{V}^{+} / \mathrm{PI}^{-}\right)$.

\section{Determination of combination index}

Combination index $(\mathrm{CI})$ was used to quantitatively determine the synergy between the drugs in combined chemotherapies. CI values were calculated based on the median-effect method of $\mathrm{Chou}^{19}$ as follows:

$$
\mathrm{CI}=\frac{\left(\mathrm{A}_{\text {comb }}\right)}{(\mathrm{A})}+\frac{\left(\mathrm{B}_{\text {comb }}\right)}{(\mathrm{B})}
$$

where $\left(\mathrm{A}_{\text {comb }}\right)$ and $\left(\mathrm{B}_{\text {comb }}\right)$ represent the concentrations of drug $A$ and drug $B$ that achieve a specific effect when used in combination, and (A) and (B) represent the concentrations of drug $\mathrm{A}$ and drug $\mathrm{B}$ that achieve the same effect as in the individual monotherapy. $\mathrm{CI}=1$ indicates an additive effect, $\mathrm{CI}<1$ indicates a synergistic effect, and $\mathrm{CI}>1$ indicates an antagonistic effect.

\section{Western blotting}

SGC-7901 cells were incubated with indicated concentrations of MK-2206 and 5-FU (or doxorubicin) for indicated time periods. Cells were harvested and lysed in radioimmunoprecipitation assay (RIPA) buffer (50 mM 4-(2-hydroxyethyl)1-piperazineethanesulfonic acid (HEPES) [pH 7.4], $150 \mathrm{mM}$ $\mathrm{NaCl}, 1 \%$ Triton X-100, $30 \mathrm{mM}$ sodium pyrophosphate, $5 \mathrm{mM}$ ethylenediaminetetraacetic acid, $2 \mathrm{mM} \mathrm{Na}_{3} \mathrm{VO}_{4}, 5 \mathrm{mM} \mathrm{NaF}, 1$ $\mathrm{mM}$ phenylmethylsulfonyl fluoride, and phosphate inhibitors). Protein concentration was measured with the bicinchoninic acid (BCA) assay (Beyotime, Shanghai, People's Republic of China).
Equal amounts of proteins were loaded on $8 \%-12 \%$ Tris-Glycine gels and transferred onto polyvinylidene fluoride membranes, which were then blocked with $5 \%$ fat-free milk in phosphatebuffered saline with $0.1 \%$ Tween 20 for 1 hour and blotted with the specific primary antibodies. The membranes were then washed with phosphate-buffered saline with $0.1 \%$ Tween 20 and incubated with the secondary antibodies. The protein-antibody complexes were then visualized using an enhanced chemiluminescence kit (Biological Industries, Cromwell, CT, USA).

\section{Statistical analysis}

Data with normal distribution and homogeneity of variance were analyzed with one-way analysis of variance (ANOVA). Otherwise, nonparametric test was used. $P<0.05$ was considered statistically significant. All statistical analyses were performed with GraphPad Prism 5 (GraphPad Software Inc, La Jolla, CA, USA).

\section{Results}

\section{Effect of MK-2206 on the proliferation} and apoptosis of gastric cancer cell lines

We first examined the antiproliferative effect of MK-2206 as a single agent in gastric cancer cells SGC-7901 and MKN45 (Figure 1A). MK-2206 inhibited the proliferation of gastric cancer cells in a dose- and time-dependent manner $(P<0.05$; two-way ANOVA followed by Bonferroni post-hoc tests), reaching a plateau at $2-8 \mu \mathrm{M}$ in SGC-7901 cells $(P=0.337$, 0.787 , and 0.728 for 24,48 , and 72 hours' treatment, respectively; one-way ANOVA) or at $2-4 \mu \mathrm{M}$ in MKN45 cells ( $P=0.990,0.817$, and 0.295 for 24,48 , and 72 hours' treatment, respectively; 2 vs $4 \mu \mathrm{M}$, Tukey's test). MK-2206 showed the $\mathrm{IC}_{50}$ values of $22.92 \pm 4.00,13.68 \pm 2.04$, and $8.55 \pm 1.88 \mu \mathrm{M}$ (estimated mean $\pm 95 \%$ confidence interval) in SGC-7901 cells and $19.21 \pm 1.45,13.10 \pm 0.96$, and $9.11 \pm 1.43 \mu \mathrm{M}$ (estimated mean $\pm 95 \%$ confidence interval) in MKN45 cells 24,48 , and 72 hours posttreatment, respectively (Table 1). Colony formation assay confirmed that $1 \mu \mathrm{M}$ of MK-2206 resulted in a significant inhibitory effect in SGC-7901 cells $(18.13 \% \pm 1.8 \%$ vs $38.87 \% \pm 5.9 \% ; P=0.004$, Student's $t$-test; Figure 1B).

Except for the growth inhibition, MK-2206 could also result in gastric cancer cell death. With increased MK-2206 dose, SGC-7901 cells gradually showed morphological changes such as shrinkage, aggregation, and spherical and micronucleation (Figure 2A), generally indicating the process of apoptosis. Further Annexin-V-FITC/PI assay confirmed the related apoptosis in gastric cancer cells caused by MK-2206 augmentation. It induced dose-dependent apoptosis, with significant increase in the early, late, and total apoptosis. However, no statistical significance was found until the concentration reached $16 \mu \mathrm{M}$ 
A

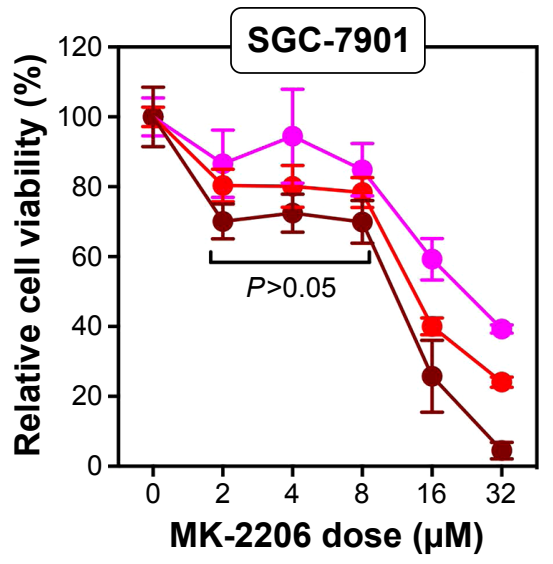

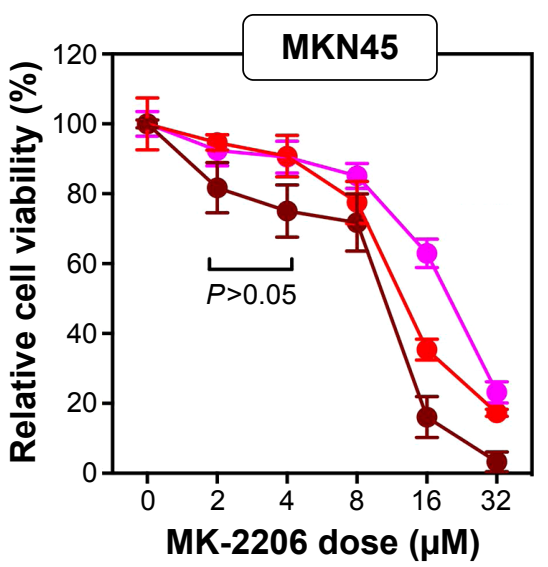
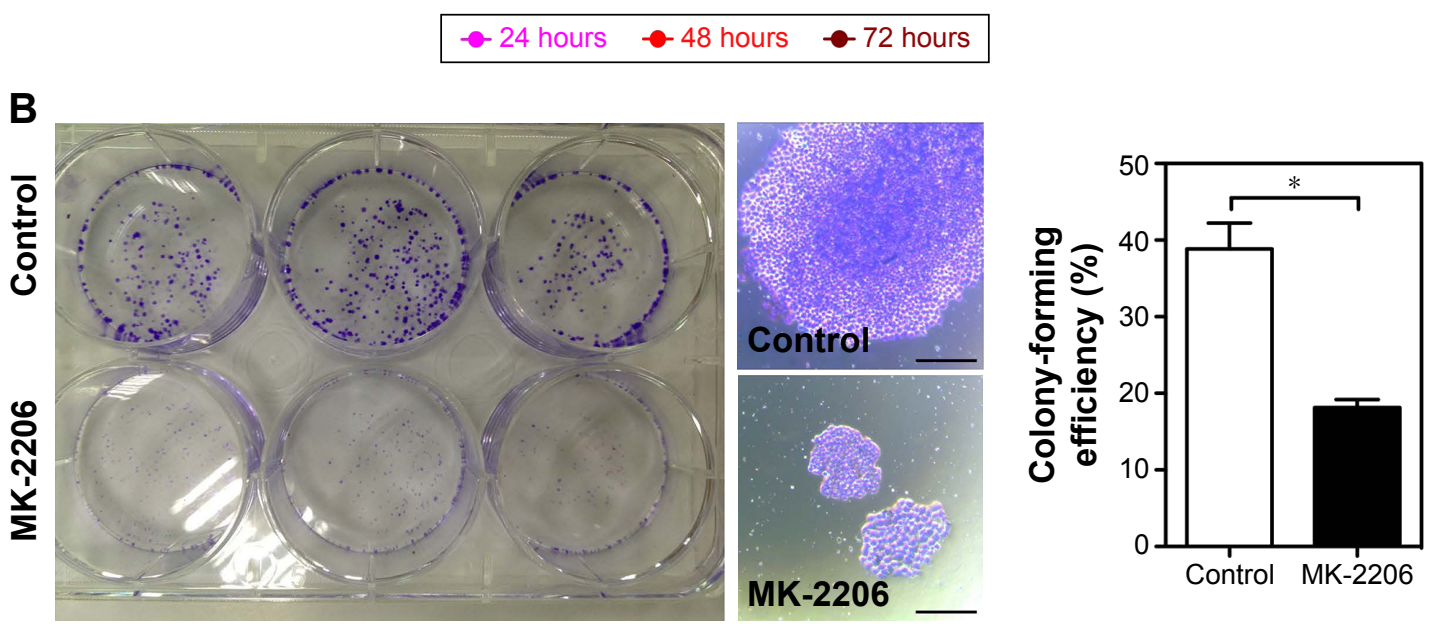

Figure I MK-2206 attenuated proliferation of gastric cancer cells.

Notes: (A) MK-2206 significantly inhibited proliferation of SGC-790I and MKN45 cells. Gastric cancer cells (3,000 per well) were treated with MK-2206 at various concentrations (2-32 $\mu \mathrm{M}$ ) or vehicle for 24, 48, and 72 hours, respectively. Cell viability was determined using CellTiter Cell Proliferation Assay. (B) Effect of MK-2206 on the colony formation of SGC-790 I cells. Treatment with MK-2206 significantly suppressed the colony formation ability of SGC-790I cells. Photographs are representative of three independent experiments (left panel); enlarged photographs are $\times 40$ magnification images of representative colonies (middle panels). The scale bar represents I00 $\mu \mathrm{m}$. Right panel shows quantitative analysis of colony formation efficiencies $(* P<0.0 \mathrm{I})$.

$(P<0.05$; one-way ANOVA followed by Tukey's tests) (Figure 2B and C). These data suggest that MK-2206 is a potent apoptosis inducer in gastric cancer cells.

\section{The combination of MK-2206 with 5-FU} or doxorubicin synergistically inhibited the proliferation of SGC-790I and MKN45 cells

5-FU and doxorubicin are two conventional chemotherapeutics for gastric cancer, which have been widely used

Table I IC ${ }_{50}$ values of MK-2206 in SGC-790I and MKN45 cells

\begin{tabular}{llll}
\hline Cell lines & \multicolumn{3}{l}{ Posttreatment duration (hours) } \\
\cline { 2 - 4 } & $\mathbf{2 4}$ & $\mathbf{4 8}$ & $\mathbf{7 2}$ \\
\hline SGC-790I & $22.92 \pm 4.00$ & $13.68 \pm 2.04$ & $8.55 \pm 1.88$ \\
MKN45 & $19.21 \pm 1.45$ & $13.10 \pm 0.96$ & $9.11 \pm 1.43$ \\
\hline
\end{tabular}

Note: $A l l I_{50}$ values are estimated by nonlinear fit model and shown as estimated value $\pm 95 \%$ confidence interval $(\mu \mathrm{M})$.

Abbreviation: $I C_{50}, 50 \%$ inhibitory concentration. in the clinical practice. ${ }^{20,21}$ To investigate the relationship between MK-2206 and the two drugs, we first assessed the effect $\left(\mathrm{IC}_{50}\right.$ values) of doxorubicin and 5-FU on gastric cancer cells and then calculated the $\mathrm{CI}$ values based on $\mathrm{IC}_{50}$ values of MK-2206 alone, chemotherapeutics alone, or their combination at a fixed ratio (Figure 3; Table 2). Referring to the combination index in Table 2, we observed a synergistic interaction between MK-2206 and doxorubicin (or 5-FU) in both SGC-7901 and MKN45 cells. Also, MK-2206 co-treatment with either doxorubicin or 5-FU was far superior to that of single drug treatments.

Western blotting was performed to evaluate the inhibitory effect of MK-2206 on Akt phosphorylation in SGC-7901 cells. As shown in Figure 4A, $1 \mu \mathrm{M}$ MK-2206 could completely inhibit the phosphorylation of Akt at Ser473 without affecting total Akt levels. The inhibitory effect was observed within 12 hours and lasted for at least 48 hours (Figure 4). On the other hand, we found that doxorubicin or 5-FU alone may increase the expression of p-Akt in a dose-dependent 

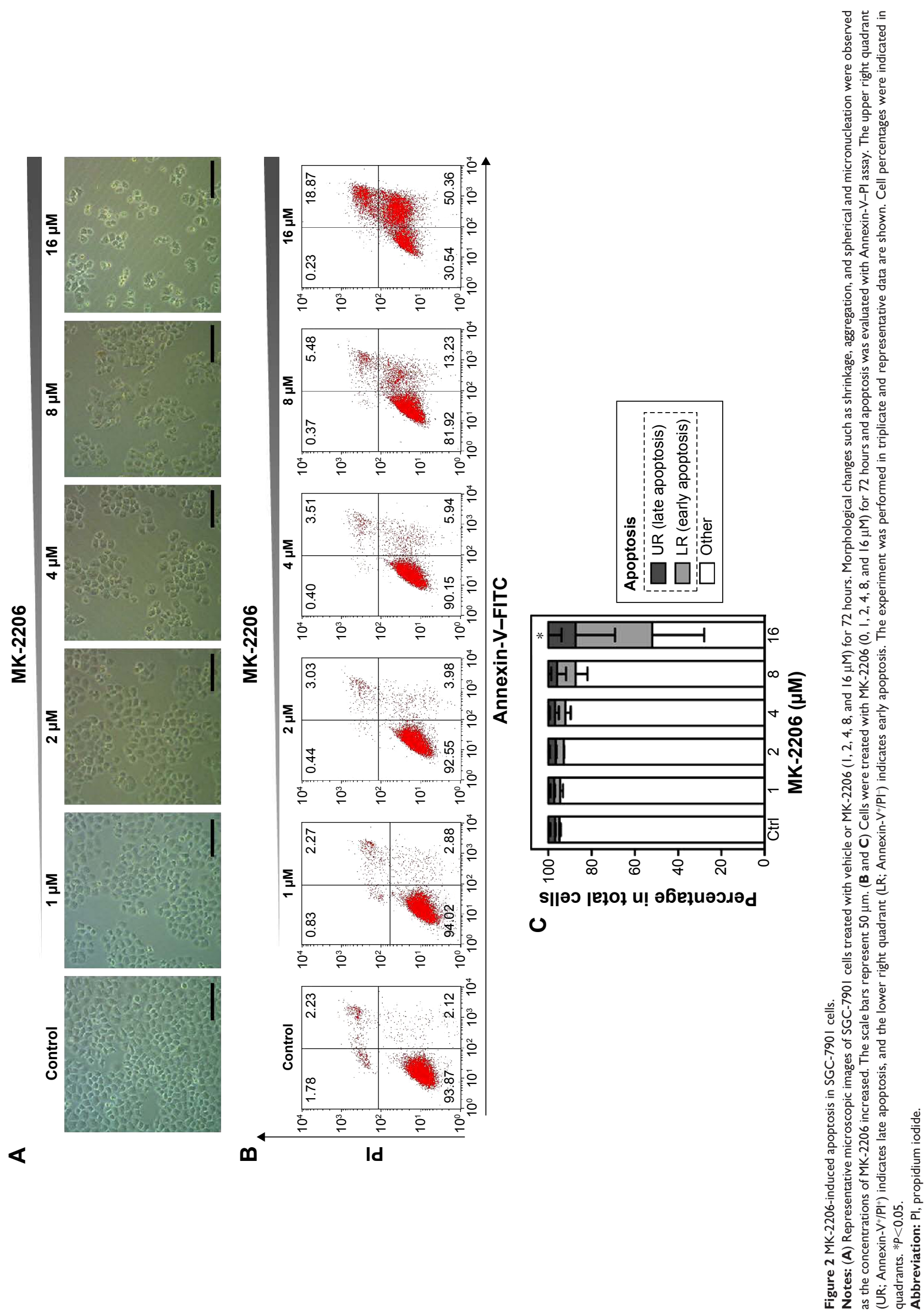
A

Doxorubicin $(\boldsymbol{\mu M})$

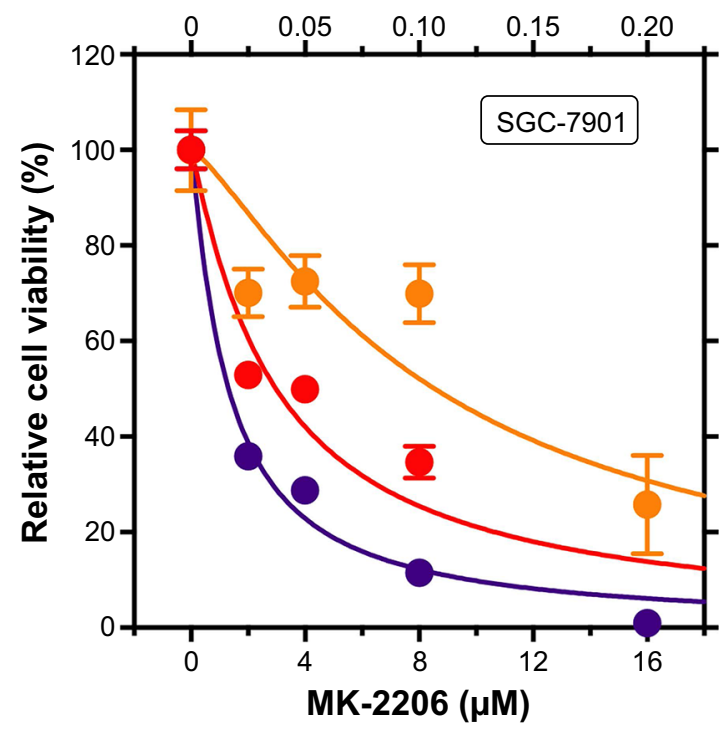

Doxorubicin $(\mu \mathrm{M})$

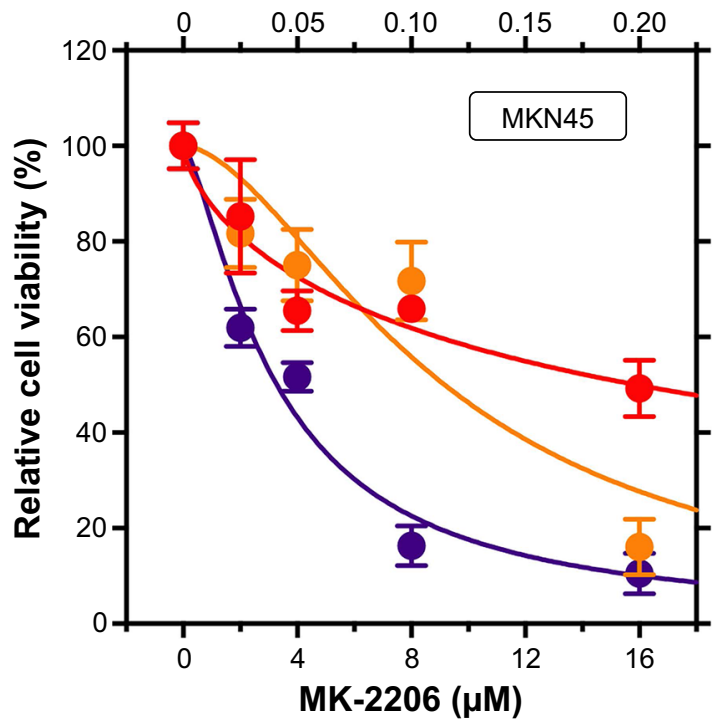

Doxorubicin - MK-2206 - Doxorubicin + MK-2206

B $5-\mathrm{FU}(\mu \mathrm{g} / \mathrm{mL})$
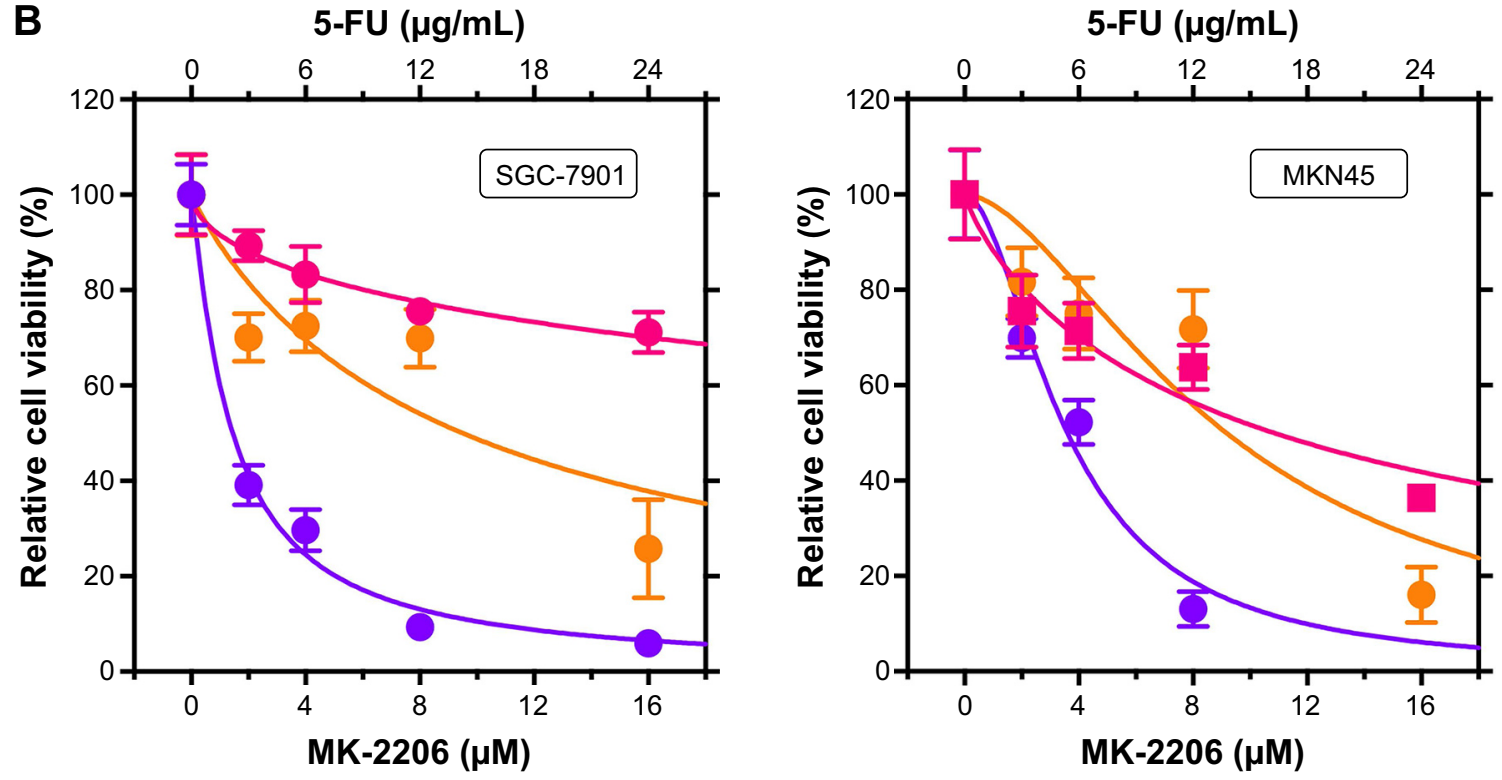

$-5-F U-\mathrm{MK}-2206-5-\mathrm{FU}+\mathrm{MK}-2206$

Figure 3 Cell viability difference between the combination treatment and two corresponding single treatments.

Notes: Cells were simultaneously treated with MK-2206 and doxorubicin (or 5-FU) at a fixed concentration ratio for 72 hours. Cell growth was evaluated by CellTiter Cell Proliferation Assay. Cl values were calculated according to the equation of median-effect method of Chou. ${ }^{19}$ (A) SGC-790I and MKN45 cells were treated with MK-2206 alone, doxorubicin alone, or MK-2206 and doxorubicin combination. (B) SGC-790I and MKN45 cells were treated with MK-2206 alone, 5-FU alone, or MK-2206 and 5-FU combination.

Abbreviations: 5-FU, 5-fluorouracil; $\mathrm{Cl}$, combination index.

Table 2 The synergistic effect of MK-2206 combined with doxorubicin or 5-FU in SGC-790I and MKN45 cells ${ }^{\mathrm{a}}$

\begin{tabular}{|c|c|c|c|c|c|c|c|}
\hline Cell lines & $\begin{array}{l}\text { MK-2206 } \\
I C_{50}(\mu M) \\
\end{array}$ & $\begin{array}{l}\text { Dox IC } C_{50} \\
(\mu \mathrm{M})\end{array}$ & $\begin{array}{l}\text { Dox/MK-2206 } \\
I C_{50}(\mu M)\end{array}$ & $\begin{array}{l}\mathrm{Cl}^{\mathrm{b}} \text { (Doxl } \\
\text { MK-2206) }\end{array}$ & $\begin{array}{l}5 \text {-FU IC } \\
(\mu \mathrm{g} / \mathrm{mL})\end{array}$ & $\begin{array}{l}\text { 5-FU/MK-2206 } \\
I_{50}(\mu \mathrm{g} / \mathrm{mL}, \mu \mathrm{M})\end{array}$ & $\mathrm{Cl}^{\mathrm{b}}(5-\mathrm{FU} / \mathrm{MK}-2206)$ \\
\hline SGC-790I & $8.55 \pm 1.88$ & $0.04 \pm 0.01$ & $0.02 \pm 0.00 / I .3 I \pm 0.28$ & 0.59 & $1 \mathrm{II} .2 \mathrm{I} \pm 95.27$ & $2.18 \pm 0.46 / I .45 \pm 0.31$ & 0.17 \\
\hline MKN45 & $9.11 \pm 1.43$ & $0.20 \pm 0.07$ & $0.04 \pm 0.01 / 3.28 \pm 0.39$ & 0.57 & $16.26 \pm 3.69$ & $5.40 \pm 0.62 / 3.60 \pm 0.4 \mathrm{I}$ & 0.73 \\
\hline
\end{tabular}

Notes: a Cells were simultaneously treated with MK-2206 and doxorubicin or 5-FU at a fixed concentration ratio for 72 hours. Cell growth was evaluated by CellTiter Cell Proliferation Assay. ${ }^{\mathrm{b}} \mathrm{Cl}$ values were calculated according to the equation of median-effect method of Chou. ${ }^{19}$

Abbreviations: 5-FU, 5-fluorouracil; Dox, doxorubicin; $\mathrm{IC}_{50}, 50 \%$ inhibitory concentration; $\mathrm{Cl}$, combination index. 
A

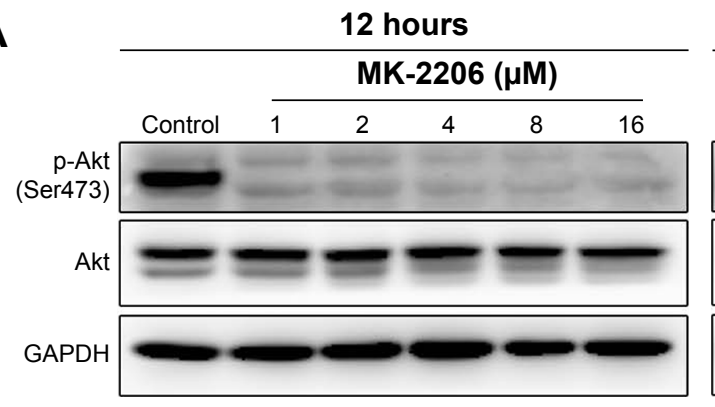

B

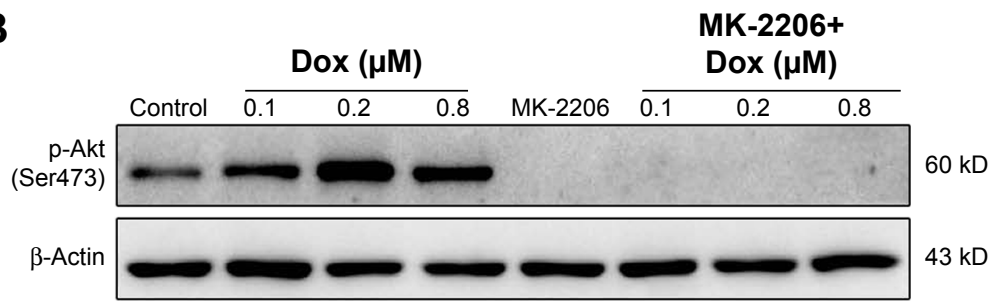

C

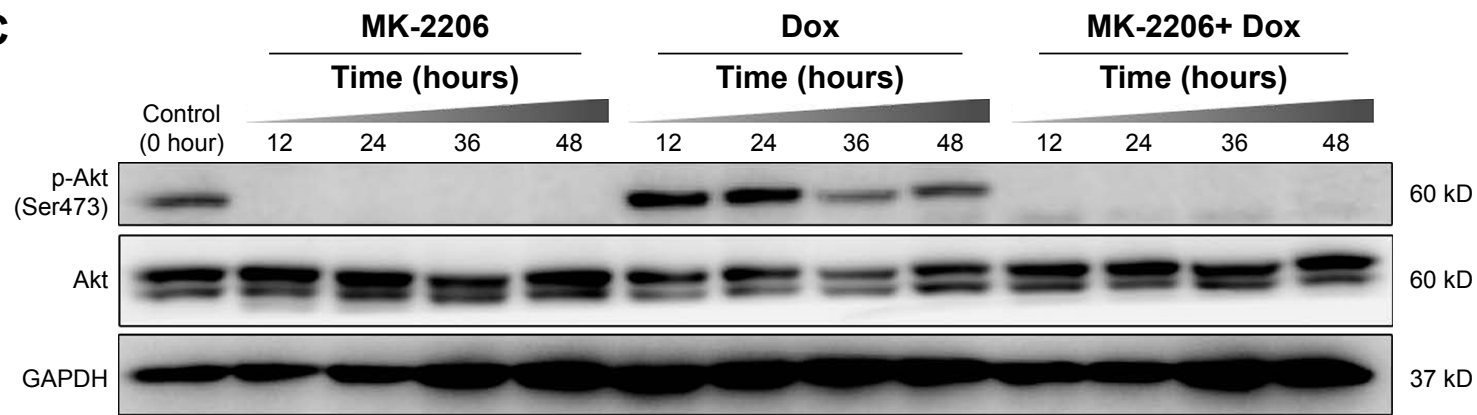

Figure 4 Effect of Akt inhibitor MK-2206 on Akt phosphorylation (p-Akt) in gastric cancer cells.

Notes: (A) Dose-dependent response. SGC-790Icells were treated with MK-2206 at the indicated concentration for 12 and 48 hours, respectively. Cell lysates were subjected to Western blotting using anti-phospho-Akt (specific to Ser473, p-Akt) and anti-Aktl/2. GAPDH was used as loading control. (B) MK-2206 inhibited the activation of Akt Ser473 induced by doxorubicin. Cells were treated with doxorubicin (0.I, 0.2, $0.8 \mu \mathrm{M}$ ) in the presence of MK-2206 (I $\mu \mathrm{M})$ for 24 hours. Cell lysates were prepared, and p-Akt expression level was determined by Western blotting. (C) Time-dependent effect of MK-2206 and doxorubicin on p-Akt in SGC-790I cells. Cells were treated with I $\mu$ M MK-2206 alone, $0.2 \mu \mathrm{M}$ doxorubicin alone, or both agents for 12, 24, 36, and 48 hours. Expression levels of p-Akt and total Akt were determined by Western blotting. Abbreviations: Dox, doxorubicin; GAPDH, glyceraldehyde-3-phosphate dehydrogenase.

manner. However, the co-treatment with $1 \mu \mathrm{M}$ MK-2206 could completely abrogate the chemotherapy-induced activation of Akt (Figure 4B). Similarly, this inhibitory effect of MK-2206 could start as early as 3 hours and remained stable within 24 hours (Figure 4C).

Since $1 \mu \mathrm{M}$ MK-2206 was able to inhibit the activation of Akt, we chose this relatively low concentration to further explore the effect of MK-2206 on the chemotherapeutic sensitivity of SGC-7901. The cleavage of caspase-9, caspase-7, caspase-3, and PARP was detected using Western blotting. Compared with doxorubicin $(0.1,0.2,0.8 \mu \mathrm{M})$ or 5 -FU $(12,24,96 \mu \mathrm{g} / \mathrm{mL})$ alone, the addition of $1 \mu \mathrm{M}$ MK-2206 could enhance the apoptosis induction in SGC-7901 cells (Figure 5). The expression of cleaved caspase-3, caspase-7, caspase-9, and PARP was significantly higher when MK-2206 was combined with $0.8 \mu \mathrm{M}$ doxorubicin or $96 \mu \mathrm{g} / \mathrm{mL} 5-\mathrm{FU}$.

\section{Discussion}

In this study, we tested the therapeutic potential of MK-2206 in gastric cancer. Our data showed that MK-2206 effectively abrogated Akt signaling and attenuated the growth of gastric cancer cells. This finding is consistent with previous reports that MK-2206 could effectively inhibit the growth of various cancer cells such as thyroid, nasopharyngeal, colorectal, and lung in vitro and in vivo. ${ }^{13,16,17,22-24}$

However, single-agent MK-2206 appeared to have a limited effect on the proliferation of gastric cancer cells at clinically relevant concentrations. At low micro-molar concentrations, the growth inhibitory effect did not exceed $30 \%$ in either SGC-7901 (2-8 $\mu \mathrm{M})$ or MKN45 cells $(2-4 \mu \mathrm{M})$. Similar results have also demonstrated that the viability of gastric cancer cell lines AGS, SNU-1, and SNU-16 decreased until the concentration of MK-2206 was $>6 \mu \mathrm{M} .{ }^{25}$ Due to 
A

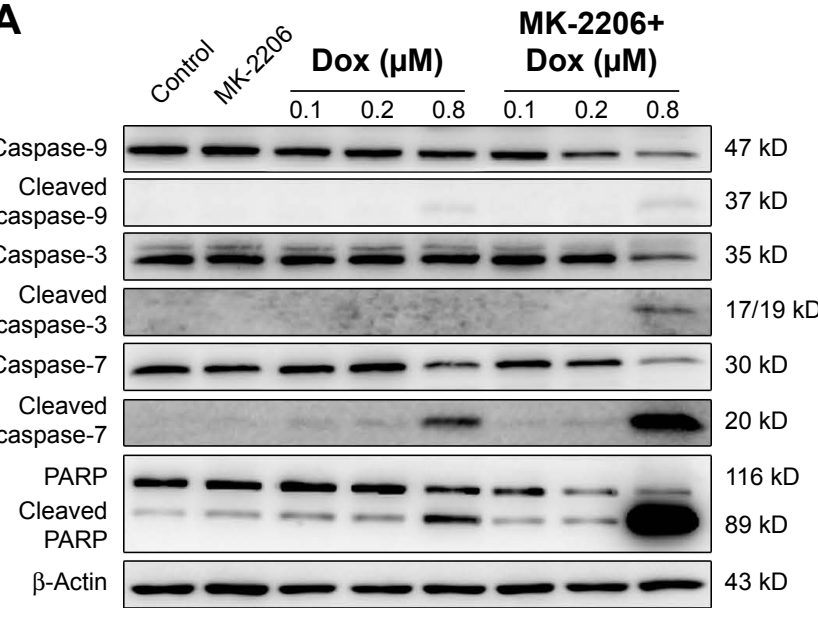

B

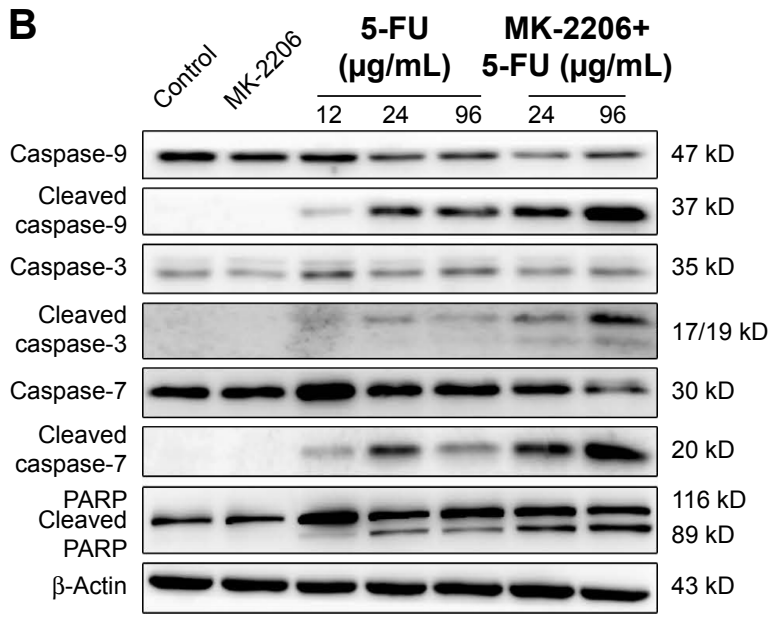

Figure 5 Effect of MK-2206 on induction of caspase cascade by doxorubicin or 5-FU.

Notes: SGC-790 I cells were treated with (A) doxorubicin $(0,0.1,0.2,0.8 \mu \mathrm{M})$ or (B) 5-FU $(0,12,24,96 \mu g / \mathrm{mL})$ in the presence of MK-2206 (I $\mu$ M) or DMSO vehicle for 24 hours. Cell lysates were prepared, and the amount of caspase-3, -7, -9, PARP and cleaved caspase-3, -7, -9, PARP were determined by Western blotting.

Abbreviations: Dox, doxorubicin; 5-FU, 5-fluorouracil; DMSO, dimethylsulfoxide; PARP, poly ADP ribose polymerase.

complex signaling networks in human cancers, the blockage of a single target molecule or pathway might be insufficient, since other molecules or alternative pathways may compensate for the inhibited component. ${ }^{13}$ Moreover, it was found in other types of cancer cells that treatment with MK-2206 induces autophagy, which might be a protective mechanism against MK-2206-induced cytotoxicity. ${ }^{26-28}$ Therefore, the mechanism that mediated the sensitivity of gastric cancer cells to MK-2206 merits further investigation.

The activation of PI3K/Akt pathway plays an important role in the biology of cancers such as tumorigenesis, tumor metastasis, and the resistance to conventional chemotherapeutic drugs. ${ }^{29}$ It was demonstrated that the addition of paclitaxel increased Akt activity, which was correlated with low level of cell death. ${ }^{30}$ Similarly, induction of Akt by cisplatin was responsible for the observed chemotherapeutic resistance. ${ }^{31}$ However, the exact mechanism of Akt activation leading to chemoresistance is unclear. ${ }^{32}$ In the present study, treatment with doxorubicin or 5-FU had a notable effect on increasing the expression of p-Akt in SGC-7901 cells. The addition of $1 \mu \mathrm{M}$ MK-2206 could effectively abrogate chemotherapyinduced Akt activation within 12 hours. It not only explains the synergism between MK-2206 and doxorubicin or 5-FU, but also raised a hypothesis that whether specific inhibition of induced Akt activation might augment the sensitivity of gastric cancer cells to conventional chemotherapy.

Previous researches have shown that the inhibition of $\mathrm{PI} 3 \mathrm{~K} /$ Akt could sensitize ovarian cancer cells to paclitaxel and increase the induction of apoptosis in colon cancer cells in combination with irinotecan. ${ }^{30,33}$ Molecule-targeted drugs such as LY294002 and rapamycin, which target other components of PI3K/Akt pathway, have been shown to be capable of restoring the chemotherapeutic sensitivity of gastric cancer cells in vitro and in vivo. ${ }^{34-36}$ MK-2206, as a potent Akt inhibitor, showed a synergistic interaction in combination with anticancer agents in various cancer cells. The presence of MK-2206 could significantly increase the inhibition of proliferation of glioma cells, when treated with gefitinib, and hepatocarcinoma cells, when treated with doxorubicin. ${ }^{26,27}$ Similarly, in gastric cancer cells, the combined therapy of MK-2206 and chemotherapies showed a more powerful inhibition of proliferation than that of a single agent.

Investigations on the mechanisms underlying the combination effect of MK-2206 on anticancer agents also revealed that cell apoptosis played an important role in the induction of cell death. Although no significantly increased apoptosis was found in SGC-7901 cells at low concentrations of MK-2206 alone $(0-12 \mu \mathrm{M})$, it could potentiate chemotherapy-induced apoptosis at concentrations as low as $1 \mu \mathrm{M}$. Caspases are a family of cell death proteases which are triggered in response to pro-apoptotic signals and play an essential role in the execution phase of apoptosis. ${ }^{37-39}$ The activation of caspases during apoptosis results in the cleavage of critical cellular substrates, including PARP, and precipitating the dramatic morphological changes of apoptosis. Western blotting analysis revealed that the addition of $1 \mu \mathrm{M}$ MK-2206 could increase the expression of cleaved caspase-3/7/9 and PARP by doxorubicin and 5-FU. Therefore, the addition of MK-2206 could effectively sensitize gastric cancer cells to chemotherapy by prompting cell apoptosis. Consistent with our observations, activation of caspase pathway was proved 
to play an important role in the enhanced cell death induction in lapatinib-treated HCC70 breast cancer cells, erlotinibtreated non-small-cell lung cancer cell line NCL-H292, and etoposide-treated neuroblastoma, when co-treated with MK-2206. ${ }^{13,14}$ Hence, suppressed activity of caspase pathway may be involved in the reduced chemotherapeutic sensitivity of gastric cancer cells mediated by PI3K/Akt pathway.

Taken together, our result provides evidence that targeting PI3K/Akt pathway using MK-2206 is an efficient therapeutic strategy for gastric cancer. This treatment potentiates the antitumor effect of chemotherapeutics via the inhibition of activated Akt and induction of caspase pathway. Therefore, the combination of MK-2206 with chemotherapeutics may be helpful to overcome chemoresistance in gastric cancer. Further in vivo studies are warranted to confirm these findings.

\section{Acknowledgments}

The work was funded by the Zhejiang provincial medical platform 2015 specialists class B (2015 RCB016) and Zhejiang province key science and technology innovation team (2013TD13).

\section{Disclosure}

The authors report no conflicts of interest in this work.

\section{References}

1. Torre LA, Bray F, Siegel RL, Ferlay J, Lortet-Tieulent J, Jemal A. Global cancer statistics, 2012. CA Cancer J Clin. 2015;65(2):87-108.

2. Power DG, Kelsen DP, Shah MA. Advanced gastric cancer - slow but steady progress. Cancer Treat Rev. 2010;36(5):384-392.

3. Song G, Ouyang G, Bao S. The activation of Akt/PKB signaling pathway and cell survival. J Cell Mol Med. 2005;9(1):59-71.

4. Osaki M, Oshimura M, Ito H. PI3K-Akt pathway: its functions and alterations in human cancer. Apoptosis. 2004;9(6):667-676.

5. Engelman JA. Targeting PI3K signalling in cancer: opportunities, challenges and limitations. Nat Rev Cancer. 2009;9(8):550-562.

6. Bellacosa A, Kumar CC, Di Cristofano A, Testa JR. Activation of AKT kinases in cancer: implications for therapeutic targeting. Adv Cancer Res. 2005;94:29-86.

7. Yang ZZ, Tschopp O, Baudry A, Dummler B, Hynx D, Hemmings BA. Physiological functions of protein kinase B/Akt. Biochem Soc Trans. 2004;32(Pt 2):350-354.

8. Samuels Y, Wang Z, Bardelli A, et al. High frequency of mutations of the PIK3CA gene in human cancers. Science. 2004;304(5670):554.

9. Suzuki H, Freije D, Nusskern DR, et al. Interfocal heterogeneity of PTEN/MMAC1 gene alterations in multiple metastatic prostate cancer tissues. Cancer Res. 1998;58(2):204-209.

10. Nam SY, Lee HS, Jung GA, et al. Akt/PKB activation in gastric carcinomas correlates with clinicopathologic variables and prognosis. APMIS. 2003;111(12):1105-1113.

11. Cinti C, Vindigni C, Zamparelli A, et al. Activated Akt as an indicator of prognosis in gastric cancer. Virchows Arch. 2008;453(5):449-455.

12. Han Z, Hong L, Han Y, et al. Phospho Akt mediates multidrug resistance of gastric cancer cells through regulation of P-gp, Bcl-2 and Bax. J Exp Clin Cancer Res. 2007;26(2):261-268.
13. Hirai H, Sootome H, Nakatsuru Y, et al. MK-2206, an allosteric Akt inhibitor, enhances antitumor efficacy by standard chemotherapeutic agents or molecular targeted drugs in vitro and in vivo. Mol Cancer Ther. 2010;9(7):1956-1967.

14. Li Z, Yan S, Attayan N, Ramalingam S, Thiele CJ. Combination of an allosteric Akt inhibitor MK-2206 with etoposide or rapamycin enhances the antitumor growth effect in neuroblastoma. Clin Cancer Res. 2012;18(13):3603-3615.

15. Jiao P, Zhou YS, Yang JX, et al. MK-2206 induces cell cycle arrest and apoptosis in HepG2 cells and sensitizes TRAIL-mediated cell death. Mol Cell Biochem. 2013;382(1-2):217-224.

16. Ma BB, Lui VW, Hui CW, et al. Preclinical evaluation of the AKT inhibitor MK-2206 in nasopharyngeal carcinoma cell lines. Invest New Drugs. 2013;31(3):567-575.

17. Liu R, Liu D, Trink E, Bojdani E, Ning G, Xing M. The Akt-specific inhibitor MK2206 selectively inhibits thyroid cancer cells harboring mutations that can activate the PI3K/Akt pathway. J Clin Endocrinol Metab. 2011;96(4):E577-E585.

18. Yap TA, Yan L, Patnaik A, et al. First-in-man clinical trial of the oral pan-AKT inhibitor MK-2206 in patients with advanced solid tumors. J Clin Oncol. 2011;29(35):4688-4695.

19. Chou TC. Drug combination studies and their synergy quantification using the Chou-Talalay method. Cancer Res. 2010;70(2): $440-446$.

20. Cunningham D, Allum WH, Stenning SP, et al. Perioperative chemotherapy versus surgery alone for resectable gastroesophageal cancer. N Engl J Med. 2006;355(1):11-20.

21. Cascinu S, Labianca R, Barone C, et al. Adjuvant treatment of high-risk, radically resected gastric cancer patients with 5-fluorouracil, leucovorin, cisplatin, and epidoxorubicin in a randomized controlled trial. $J$ Natl Cancer Inst. 2007;99(8):601-607.

22. Agarwal E, Chaudhuri A, Leiphrakpam PD, Haferbier KL, Brattain MG, Chowdhury S. Akt inhibitor MK-2206 promotes anti-tumor activity and cell death by modulation of AIF and Ezrin in colorectal cancer. BMC Cancer. 2014;14:145.

23. Duan L, Perez RE, Hansen M, Gitelis S, Maki CG. Increasing cisplatin sensitivity by schedule-dependent inhibition of AKT and Chk1. Cancer Biol Ther. 2014;15(12):1600-1612.

24. Ji D, Zhang Z, Cheng L, et al. The combination of RAD001 and MK-2206 exerts synergistic cytotoxic effects against PTEN mutant gastric cancer cells: involvement of MAPK-dependent autophagic, but not apoptotic cell death pathway. PLoS One. 2014;9(1):e85116.

25. Almhanna K, Cubitt CL, Zhang S, et al. MK-2206, an Akt inhibitor, enhances carboplatinum/paclitaxel efficacy in gastric cancer cell lines. Cancer Biol Ther. 2013;14(10):932-936.

26. Simioni C, Martelli AM, Cani A, et al. The AKT inhibitor MK-2206 is cytotoxic in hepatocarcinoma cells displaying hyperphosphorylated AKT-1 and synergizes with conventional chemotherapy. Oncotarget. 2013;4(9):1496-1506.

27. Cheng Y, Zhang Y, Zhang L, et al. MK-2206, a novel allosteric inhibitor of Akt, synergizes with gefitinib against malignant glioma via modulating both autophagy and apoptosis. Mol Cancer Ther. 2012;11(1): 154-164.

28. Simioni C, Neri LM, Tabellini G, et al. Cytotoxic activity of the novel Akt inhibitor, MK-2206, in T-cell acute lymphoblastic leukemia. Leukemia. 2012;26(11):2336-2342.

29. West KA, Castillo SS, Dennis PA. Activation of the PI3K/Akt pathway and chemotherapeutic resistance. Drug Resist Updat. 2002;5(6): 234-248.

30. Mabuchi S, Ohmichi M, Kimura A, et al. Inhibition of phosphorylation of BAD and Raf-1 by Akt sensitizes human ovarian cancer cells to paclitaxel. J Biol Chem. 2002;277(36):33490-33500.

31. Hayakawa J, Ohmichi M, Tasaka K, et al. Regulation of the PRL promoter by Akt through cAMP response element binding protein. Endocrinology. 2002;143(1):13-22.

32. Almhanna K, Strosberg J, Malafa M. Targeting AKT protein kinase in gastric cancer. Anticancer Res. 2011;31(12):4387-4392. 
33. Mueller A, Bachmann E, Linnig M, et al. Selective PI $3 \mathrm{~K}$ inhibition by BKM120 and BEZ235 alone or in combination with chemotherapy in wild-type and mutated human gastrointestinal cancer cell lines. Cancer Chemother Pharmacol. 2012;69(6):1601-1615.

34. Shin JY, Kim JO, Lee SK, Chae HS, Kang JH. LY294002 may overcome 5-FU resistance via down-regulation of activated p-AKT in Epstein-Barr virus-positive gastric cancer cells. BMC Cancer. 2010;10:425.

35. Xie X, Tang B, Zhou J, Gao Q, Zhang P. Inhibition of the PI3K/Akt pathway increases the chemosensitivity of gastric cancer to vincristine. Oncol Rep. 2013;30(2):773-782.
36. Matsuzaki T, Yashiro M, Kaizaki R, et al. Synergistic antiproliferative effect of mTOR inhibitors in combination with 5-fluorouracil in scirrhous gastric cancer. Cancer Sci. 2009;100(12):2402-2410.

37. Thornberry NA, Lazebnik Y. Caspases: enemies within. Science. 1998; 281(5381):1312-1316.

38. Wolf BB, Green DR. Suicidal tendencies: apoptotic cell death by caspase family proteinases. J Biol Chem. 1999;274(29):20049-20052.

39. Kaushal GP, Kaushal V, Hong X, Shah SV. Role and regulation of activation of caspases in cisplatin-induced injury to renal tubular epithelial cells. Kidney Int. 2001;60(5):1726-1736.

\section{Publish your work in this journal}

OncoTargets and Therapy is an international, peer-reviewed, open access journal focusing on the pathological basis of all cancers, potential targets for therapy and treatment protocols employed to improve the management of cancer patients. The journal also focuses on the impact of management programs and new therapeutic agents and protocols on

\section{Dovepress}

patient perspectives such as quality of life, adherence and satisfaction. The manuscript management system is completely online and includes a very quick and fair peer-review system, which is all easy to use. Visit http://www.dovepress.com/testimonials.php to read real quotes from published authors. 